\title{
A Novel Online Parameter Identification Algorithm for Fractional-Order Equivalent Circuit Model of Lithium-Ion Batteries
}

\author{
Lan $\mathrm{Li}^{1}$, Huarong $\mathrm{Zhu}^{2}$, Anjian $\mathrm{Zhou}^{2}$, Minghui $\mathrm{Hu}^{1,{ }^{*}}$, Chunyun $\mathrm{Fu}^{1}$, Datong Qin ${ }^{1}$ \\ ${ }^{1}$ State Key Laboratory of Mechanical Transmissions, School of Automotive Engineering, Chongqing \\ University, Chongqing 400044, China. \\ ${ }^{2}$ Chongqing Changan Automobile Co., Ltd., Chongqing 400023, China. \\ *E-mail: minghui_h@163.com
}

doi: $10.20964 / 2020.07 .29$

Received: 6 March 2020 / Accepted: 21 April 2020 / Published: 10 June 2020

\begin{abstract}
Since the parameters of lithium-ion batteries are time-varying, employing a battery model with fixed parameters poses adverse effects to the accuracy of battery state parameter (e.g. state of charge (SOC) and state of health $(\mathrm{SOH})$ ) estimation. Thus, it is highly necessary to identify the battery model parameters online to improve the accuracy of battery model. In this study, a fractional-order equivalent circuit model of lithium-ion batteries is established based on second-order RC model and the parameters of the model are identified off-line by the mixed-swarm-based cooperative particle swarm optimization (MCPSO) algorithm. In order to take into account the parameter variations and improve the accuracy of battery model, the model parameters are updated online by the recursive least square (RLS) method to achieve model parameter online identification. Simulation results show that under different cyclic test conditions (i.e. HPPC, DST, and FUDS), the root-mean-square error (RMSE) values of the fractionalorder equivalent circuit model based on the real-time update of RLS parameters are less than $9 \mathrm{mV}$, and the average relative error does not exceed $0.1 \%$, which has higher accuracy and good robustness. The results achieved in this study provide great potential for enhancing estimation accuracies of SOC and $\mathrm{SOH}$ for battery management systems (BMSs).
\end{abstract}

Keywords: lithium-ion battery; fractional-order model; online parameters identification; recursive least squares

\section{$\underline{\text { FULL TEXT }}$}

(C) 2020 The Authors. Published by ESG (www.electrochemsci.org). This article is an open access article distributed under the terms and conditions of the Creative Commons Attribution license (http://creativecommons.org/licenses/by/4.0/). 